\title{
Identification and treatment of the vulnerable coronary plaque
}

\author{
Anna van Veelen ${ }^{1, \dagger}$, Niels M.R. van der Sangen ${ }^{1, \dagger}$, José P.S. Henriques ${ }^{1}$, \\ Bimmer E.P.M. Claessen ${ }^{1, *}$ \\ ${ }^{1}$ Department of Cardiology, Heart Center, Amsterdam UMC, University of Amsterdam, Amsterdam Cardiovascular Sciences, 1105 AZ Amsterdam, \\ The Netherlands \\ *Correspondence: b.e.claessen@amsterdamumc.nl (Bimmer E.P.M. Claessen) \\ ${ }^{\dagger}$ These authors contributed equally. \\ Academic Editors: Ceolotto Giulio and Teruo Inoue \\ Submitted: 3 November 2021 Revised: 10 December 2021 Accepted: 27 December 2021 Published: 20 January 2022
}

\begin{abstract}
Acute coronary syndrome mostly arises from rupture or erosion of a vulnerable plaque. Vulnerable plaques typically appear as lipidrich plaques with a thin cap, called thin-cap fibroatheromas. Various intracoronary imaging techniques can be used to detect vulnerable plaques, such as intravascular ultrasound (IVUS), optical coherence tomography (OCT) and near-infrared spectroscopy (NIRS), each visualizing different high-risk plaque characteristics. IVUS and its post-processing techniques, such as virtual histology IVUS, can primarily be used to identify calcified and soft plaques, while OCT is also able to quantitatively measure the cap thickness. The addition of NIRS allows the exact measurement of lipid content in the plaque. Non-invasive imaging techniques to identify vulnerable plaques, such as computed tomography, are less often used but are evolving and may be of additional diagnostic use, especially when prophylactic treatments for vulnerable plaques are further established. Pharmacological treatment with lipid-lowering or anti-inflammatory medication leads to plaque stabilization and reduction of cardiovascular events. Moreover, the implantation of a stent or scaffold for the local treatment of vulnerable plaques has been found to be safe and to stabilize high-risk plaque features. The use of drug-coated balloons to treat vulnerable plaques is the subject of ongoing research. Future studies should focus on non-invasive imaging techniques to adequately identify vulnerable plaques and further randomized clinical studies are necessary to find the most appropriate treatment strategy for vulnerable plaques.
\end{abstract}

Keywords: Vulnerable plaque; Atherosclerosis; Acute coronary syndrome; Intracoronary imaging; Non-invasive imaging

\section{Introduction}

Since the introduction of percutaneous coronary intervention (PCI) in the 1970s, the mortality rates of chronic coronary syndrome (CCS) and acute coronary syndrome (ACS) have steadily decreased [1,2]. However, ischemic heart disease is still a major cause of death and disability and it accounts for approximately one-third of all deaths in people older than 35 years [3]. The American Heart Association (AHA) estimated that ischemic heart disease, and specifically ACS, accounts for around $\$ 150$ billion health costs in the United States each year [4]. Even patients with prior PCI for ACS who are on guideline-directed secondary preventive therapy, have a significant residual risk for repeat coronary events. In the first year, this risk is mainly driven by target-lesion related events (e.g., stent-related), while in the years succeeding the residual risk primarily arises from lesions in other coronary segments, which were often not considered rupture-prone during the initial PCI [5]. Therefore, early identification of these lesions responsible for (recurrent) coronary events could be of clinical significance and preventive treatment of these lesions might reduce disease burden and related health costs.

In 1989, Muller et al. [6] introduced the concept "vulnerable plaque" for-often hemodynamically insignificant - coronary plaques that were at increased risk for rupture. It was observed that in most cases of ACS, the stenosis grade of the culprit was mild (i.e., $<60 \%$ diameter stenosis), and most obstruction was caused by the formation of a thrombus [7,8]. A decade later, in 2003, Naghavi et al. $[9,10]$ provided the first consensus documents on vulnerable plaques. Since then, numerous studies have focused on vulnerable plaques to better understand the concept and the prevalence. The challenge for future studies now lies in finding the optimal detection modality and treatment option for vulnerable plaques [11]. In this review we provide a contemporary overview of (i) the morphology, (ii) the identification and (iii) possible treatment strategies of vulnerable plaques.

\section{The vulnerable plaque}

The term "vulnerable plaque" is typically used for plaques that are prone to cause a coronary event, either by rupture or erosion causing acute thrombosis, or by rapid plaque progression leading to significant stenosis and subsequent flow limitation [9]. The highest disease and mortality burden in cardiovascular disease is caused by ACS, which in the majority of cases results from (sub-)total occlusion of the coronary artery due to thrombotic obstruc- 


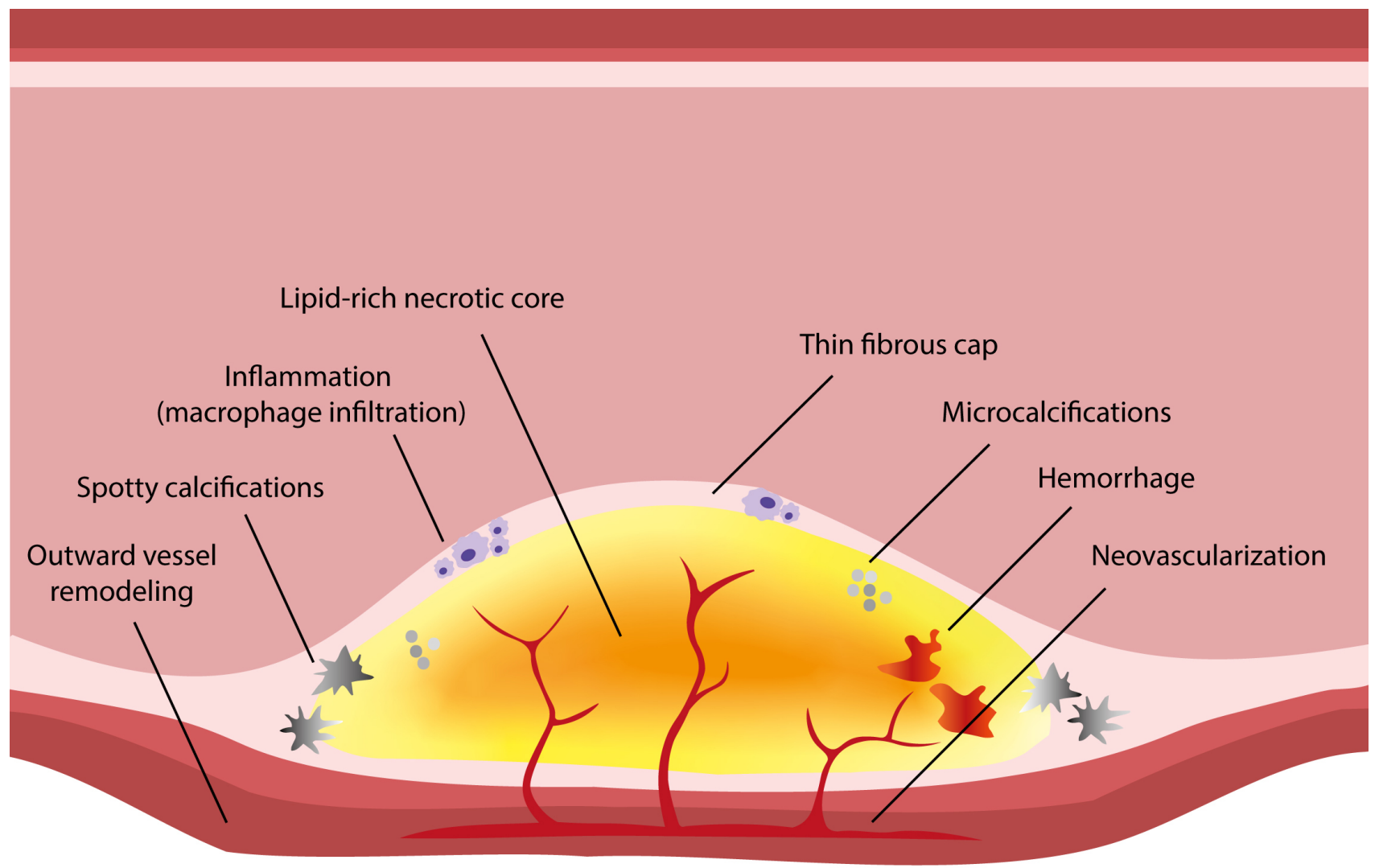

Fig. 1. Schematic overview of vulnerable plaque features. Schematic representation of a vulnerable coronary plaque. The lipid-rich necrotic core is centered in the plaque and separated from the lumen by a thin fibrous cap $(<65 \mu \mathrm{m})$, that is infiltrated by inflammatory cell types such as macrophages. Spotty calcifications and microcalcifications are present and neovascularization from the vasa vasorum leads to intraplaque hemorrhage. To prevent lumen compromise, outward vessel remodeling is present.

tion [12]. The formation of an intraluminal thrombus is usually precipitated by plaque rupture, which causes the release of thrombogenic factors leading to platelet aggregation and thrombin formation [13]. It is therefore of clinical importance to detect these rupture-prone plaques in an early stage. Accordingly, several studies retrospectively reviewed previous coronary angiography images of patients that presented with myocardial infarction (MI) to understand the morphology of the ruptured plaques causing the event [14-16]. It was found that those lesions causing a repeat event were often non-obstructive with $<50 \%$ diameter stenosis during the initial coronary angiography. Therefore, research then focused on the plaque morphology to identify plaque features that make these non-obstructive plaques vulnerable for rupture. One of these specific characteristics was observed by Libby in 1995, who found that those vulnerable plaques often had a large lipid-rich core, and can therefore be referred to as atheroma or lipid-rich plaques [17]. Lipid accumulation in the coronary artery wall arises when minimal endothelial injury occurs at locations with low endothelial shear stress, for instance at bending points or near side branches [18]. In case of plaque rupture or erosion, the lipid-rich plaque releases its content into the circulation, activating tissue factor and the coagulation cascade and, in parallel, attracting circulating platelets [19]. The interaction between the released plaque components, platelets receptors and coagulation factors subsequently leads to further platelet aggregation and thrombus formation [19]. Therefore, the quality of the cap overlying the lipid core affects the risk for plaque rupture. Plaque rupture results from a disruption of the interplay between cap strength and local plaque stress. The local plaque stress is a consequence of the high fibrous cap stiffness and high endothelial shear stress [20,21]. A post-mortem study by Burke et al. [22] in a total of 113 men showed that most ruptured plaques had only a thin fibrous cap, with a mean thickness of $23 \mu \mathrm{m}$ and $95 \%$ of ruptured plaques with a thickness of $<64 \mu \mathrm{m}$. The specific histopathological description of this rupture-prone plaque is therefore called a thin-cap fibroatheroma (TCFA) [23,24], see Fig. 1.

The AHA proposed a scheme to classify advanced atherosclerotic plaques according to plaque type $[25,26]$. This classification scheme ranges from the initial fatty streak, as found in children and adolescents (Type I) to more advanced lesions with lipid-rich, confluent and necrotic cores (Type IV), lesions with calcifications or large fibrous 


\section{Type I lesion}

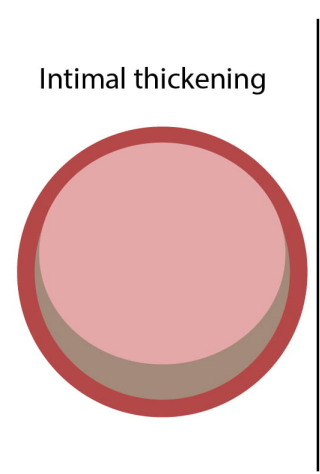

Type II lesion

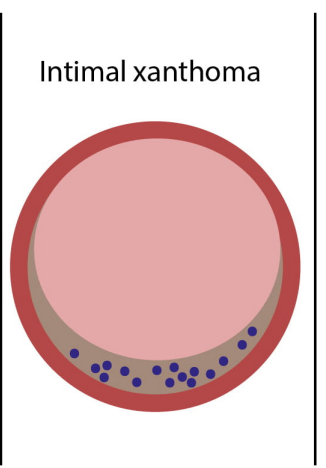

Type III lesion

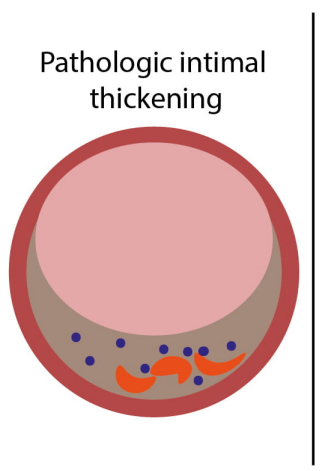

Type IV lesion

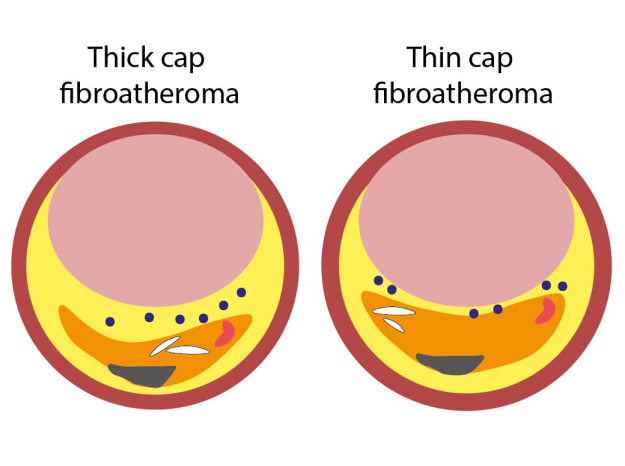

Type V lesion

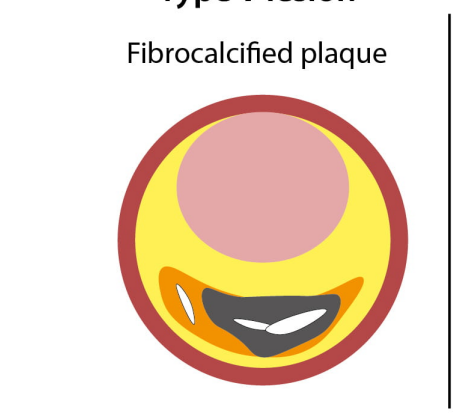

Type VI lesion (complicated)
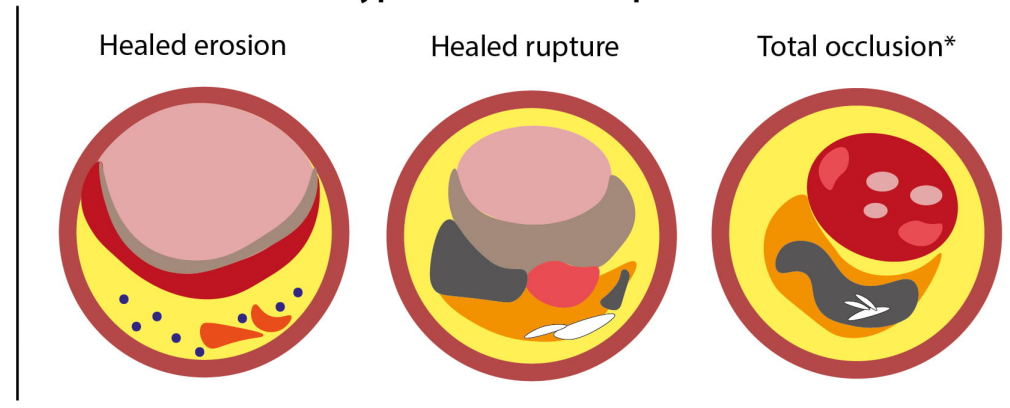

Lumen

- Extracellular lipid

Necrotic lipid core

(Healed) thrombus

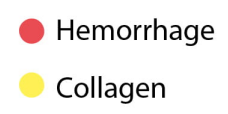

Smooth muscle cells

Calcified plaque

Fig. 2. Classification of coronary atherosclerosis. Integrated coronary plaque classification based on the American Heart Association [26] and Virmani schemes [24]. * Total occlusion as resulting from prior thrombi.

caps (Type V) or complicated lesions (Type VI). However, the classification implies that plaque evolution occurs following a linear pattern, which is often not the case. Therefore, Virmani et al. [24] suggested an alteration classification where the more advanced (Type IV-VI) lesions are described according to a more histopathological approach. According to the authors, a TCFA corresponds with a type IV atherosclerotic plaque according to the AHA classification schema [24,26]. Fig. 2 displays a schematic overview of the different plaque types.

Naghavi et al. $[9,10]$ wrote a consensus document to uniformly define vulnerable plaques. The authors advice to use the term "vulnerable plaque" for "all thrombosisprone plaques and plaques with a high probability of undergoing rapid progression, thus becoming culprit plaques". Five major criteria for a vulnerable plaque have been identified: (1) the presence of a thin cap with large lipid core; (2) the presence of active inflammation (i.e., infiltration of macrophages); (3) endothelial denudation with superficial platelet aggregation (i.e., erosion); (4) a fissured plaque (mostly indicating recent rupture) and (5) stenosis $>90 \%$. Minor criteria include the presence of superficial calcified nodules, glistening yellow plaque on angioscopy, in- traplaque hemorrhage, endothelial dysfunction or outward remodeling [9]. In this review we refer to the term "vulnerable plaque" for the lipid-rich rupture-prone plaques.

The first prospective natural history study to correlate plaque characteristics to subsequent cardiovascular events was the PROSPECT study, conducted between 2004 and 2006 [27]. This study included almost 700 patients treated with PCI for ACS who underwent additional 3-vessel angiography and intravascular ultrasonography (IVUS). Major adverse cardiovascular events (MACE), consisting of cardiac death, cardiac arrest, MI or rehospitalization for unstable or progressive angina, were adjudicated to be either related to the initial culprit lesion, or to an additional nonculprit lesion. The PROSPECT investigators found that approximately $20 \%$ of patients experienced follow-up events, equally attributable to culprit and non-culprit lesions, in the 3 years following successful PCI. The majority of nonculprit events was a result of angiographic mild lesions with a mean diameter stenosis of $32 \%$ and one-third of the lesions with a diameter stenosis of $<30 \%$. Analysis of the 3vessel IVUS images (both gray-scale and virtual-histology) revealed an average of 2 TCFAs in half of the studied patients. This was, together with a plaque burden $>70 \%$, the 
most important predictor for long-term non-culprit events. Interestingly, almost none of the non-culprit events arose from non-TCFA plaques.

These findings were confirmed in the recently published PROSPECT II study [28]. This was a prospective natural history study using 3 -vessel IVUS with coregistration of near-infrared spectroscopy (NIRS) in almost 900 patients with recent myocardial infarction. Patients were clinically followed-up for 4 years and again a large plaque burden of $>70 \%$ was predictive for non-culprit MACE (adjusted odds ratio of 3.49 on a patient level and 12.94 on a plaque level), as well as a high lipid burden as measured with NIRS (adjusted odds ratio of 2.27 on a patient level and 7.83 on a plaque level). On the contrary, plaques lacking these high-risk features were found to have a favorable long-term prognosis.

The identification of lesions causing non-culprit events might become even more important, as the risk of culprit events by in-stent restenosis and (very) late stent thrombosis has declined considerably since the advent of newer generation drug-eluting stents (DES).

\section{Identification of the vulnerable plaque}

\subsection{Invasive imaging techniques to detect vulnerable plaques}

Assessment of plain angiography images may inform the operator about lesion specifics such as the presence of calcifications, thrombosis, or the extent of luminal obstruction as expressed in percentage of diameter stenosis. However, morphological characteristics of plaques cannot be distinguished without the use of intracoronary imaging. Several techniques exist to characterize plaques. Here we describe the most commonly used intracoronary imaging techniques: IVUS, optical coherence tomography (OCT) and NIRS, which are also summarized in Table 1 (Ref. [2954]).

\subsubsection{Intravascular ultrasound}

IVUS is an invasive imaging technique that uses ultrasound to visualize the inside of the coronary artery walls [55]. The technique is built on the principles of ultrasonography, where high-energy sound waves are radiated into the tissue, and the reflection is returned to the transducer and converted into images. Echogenic components with acoustic shadowing indicate the presence of calcium, while echolucent components may indicate "soft plaque" [30,31]. IVUS has a high tissue penetration ( $4-8 \mathrm{~mm}$ ), enabling the evaluation of the entire coronary artery structure (including the external elastic membrane), but it traditionally had a limited resolution (axial 100-150 $\mu \mathrm{m}$ and lateral $200 \mu \mathrm{m}$ ), although modern IVUS systems such as the high definition (HD) IVUS system (ACIST medical systems, Eden Prarie, MN, USA), OptiCross IVUS (Boston Scientific, Marlborough, MA, USA) and the Makoto intravascular imaging system (Nipro, Bridgewater Township, NJ, USA) boast ax- ial resolutions as low as 40,22 , and $20 \mu \mathrm{m}$, respectively $[53,56]$.

Conventional grayscale IVUS can be used for the assessment of luminal dimensions and plaque morphology and to evaluate stent deployment. With grayscale IVUS, the plaque burden can be measured using the following formula: $\frac{(\text { total vessel area-lumen area) }}{\text { total vessel area }} \times 100 \%$ [46]. Plaque burden corresponds with the atheroma area and was found to be the strongest predictor for MACE in the PROSPECT study [27]. Vulnerable plaques associated with ACS present with greater plaque burden than stable plaques [42]. In order to overcome the limitation of grayscale IVUS that lipid and fibrous content are hard to distinguish, post-processing IVUS-based methods were introduced that use the backscattered radiofrequency signal to enhance tissue characterization [57]. Examples are virtual histology IVUS (VH-IVUS), Integrated Backscatter IVUS (IB-IVUS), iMAP-IVUS (Boston Scientific, Marlborough, MA, USA) and Automated Differential Echogenicity (ADE). These techniques provide more insight into the plaque composition and vulnerability and could for instance visualize the presence of a necrotic core [56,58]. The reported sensitivity and specificity of (VH)IVUS to identify TCFAs, based on pathology studies, varies between $64-92 \%$ and $78-93 \%$ respectively $[59,60]$.

\subsubsection{Optical coherence tomography}

OCT uses coherent near infrared light to generate images by measuring the intensity of light returning from the vessel wall. Due to its high resolution (10-20 $\mu \mathrm{m})$, OCT has become a frequently used imaging modality for vessel wall characterization and plaque quantification [61]. Lipid tissues (e.g., lipid-rich plaques) appear as signal-low regions with diffuse borders, while fibrous tissues present as homogeneous signal-rich regions with low attenuation [32]. As a result, OCT can visualize important features of (potential) vulnerable plaques, such as the thin fibrous cap and underlying lipid core [29], Fig. 3. Other hallmarks of plaques such as cholesterol crystals, calcifications, neovascularization and macrophage infiltration can also be characterized by OCT $[38,44]$. An important limitation of vulnerable plaque detection and characterization via OCT is the poor tissue penetration of this modality, e.g., when lipid deposits are covered by a calcified cap. Pathological validation studies have shown a high sensitivity (90-94\%) and specificity (90-92\%) of OCT to detect lipid-rich plaques [62]. Others have suggested that OCT is less suitable to distinguish TCFAs from non-TCFAs (positive predictive value [PPV] $41 \%$ ) and overestimates the incidence of TCFAs [60].

\subsubsection{Near-infrared spectroscopy}

NIRS is a relatively new catheter-based imaging modality developed to detect lipid-rich plaques [36], Fig. 4. The NIRS system provides a spatial map of lipid distribution in the coronary artery wall, a chemogram, and produces 
Table 1. Imaging modalities to detect vulnerable plaques.

\begin{tabular}{|c|c|c|c|c|c|c|}
\hline & \multicolumn{3}{|c|}{ Invasive imaging modalities } & \multicolumn{3}{|c|}{ Non-invasive imaging modalities } \\
\hline & $\begin{array}{c}\text { Intravascular } \\
\text { ultrasound (IVUS) }\end{array}$ & $\begin{array}{l}\text { Optical coherence } \\
\text { tomography (OCT) }\end{array}$ & Near-infrared spectroscopy (NIRS) & $\begin{array}{c}\text { Coronary angiography } \\
\text { computed tomography (CTCA) }\end{array}$ & $\begin{array}{l}\text { Cardiovascular magnetic } \\
\text { resonance imaging (CMR) }\end{array}$ & Nuclear imaging \\
\hline \multicolumn{7}{|l|}{ Plaque features } \\
\hline Cap thickness & - & $++[29]$ & - & - & - & - \\
\hline Lipid core & $+[30,31]$ & $+[32]$ & $++[33-36]$ & $-/+$ & $+[37]$ & - \\
\hline Inflammation & - & $++[38]$ & - & - & - & $++[39,40]$ \\
\hline Plaque erosion/rupture & $+[41,42]$ & $++[43]$ & - & - & - & - \\
\hline Microcalcifications & $++[30,31]$ & $+[44]$ & - & - & $+[37]$ & $+[45]$ \\
\hline Plaque burden & $++[46]$ & $+[47]$ & - & $+[48,49]$ & - & - \\
\hline Vessel remodeling & $++[50]$ & - & - & $++[51,52]$ & - & - \\
\hline \multicolumn{7}{|l|}{ Technical features } \\
\hline Image source & Ultrasound & Near-infrared light & Near-infrared light & $\mathrm{CT}$ & MRI & $\mathrm{CT}$ \\
\hline Guide catheter size, Fr & 5 & $5 / 6$ & 5 & N/A & N/A & N/A \\
\hline Penetration depth, mm & $4-8[53,54]$ & $1-2[53,54]$ & $1-2[53,54]$ & N/A & N/A & N/A \\
\hline Spatial resolution & $40-100 \mathrm{~mm}[53,54]$ & $10-20 \mathrm{~mm}[53,54]$ & N/A & $0.35 \mathrm{~mm}$ & $2 \mathrm{~mm}$ & $4-5 \mathrm{~mm}$ \\
\hline Temporal resolution & N/A & N/A & N/A & $80 \mathrm{~ms}$ & $25-50 \mathrm{~ms}$ & $90 \mathrm{~ms}$ \\
\hline Iodine-based contrast tracer & - & + & - & + & - & - \\
\hline Radionuclide tracer & - & - & - & - & - & + \\
\hline Radiation exposure & $-1+*$ & + & $-1+*$ & + & - & ++ \\
\hline
\end{tabular}




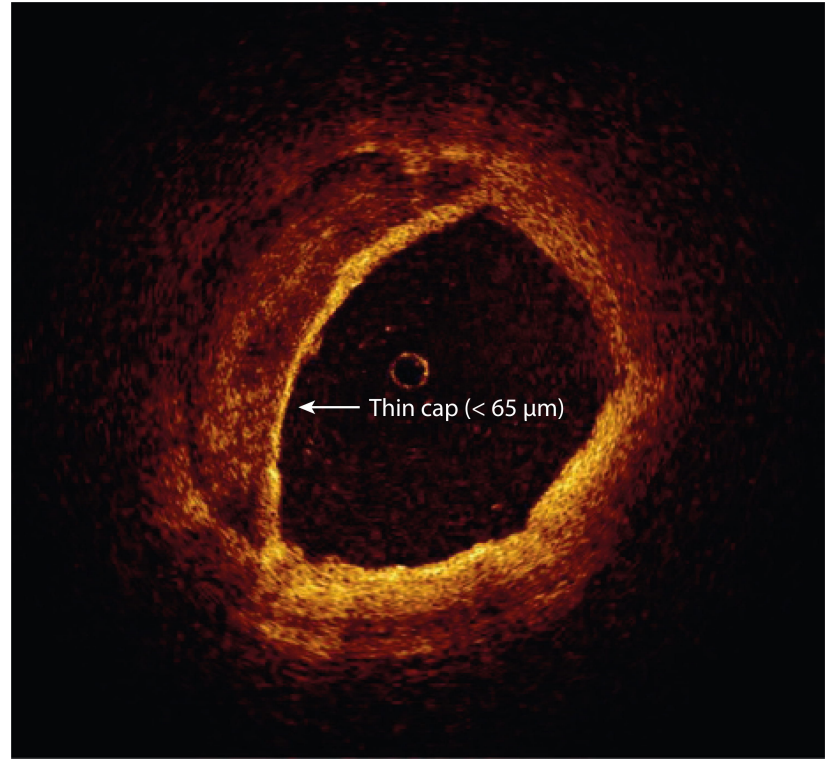

Fig. 3. Fibrous cap measurement on optical coherence tomography. A cross-section of the coronary artery with OCT demonstrates a plaque with overlying bright structure corresponding with the fibrous cap. The high resolution of OCT allows measurement of the fibrous cap, which in this case measures less than $65 \mu \mathrm{m}$, i.e., thin-cap. Image adapted from Hau WKT, Yan BPY [63]. Role of Intravascular Imaging in Primary PCI.

a quantification of the amount of lipid, called the lipid core burden index (LCBI). To combine the chemogram with morphological imaging of the coronary vessel and plaque structure, NIRS is usually combined in an integrated catheter with either IVUS (IVUS-NIRS) or, less commonly, with OCT (OCT-NIRS) [64-66].

In 2013, Madder et al. [34] demonstrated that a maximum LCBI per $4 \mathrm{~mm}$ segment (maxLCBI $4 \mathrm{~mm}$ ) of more than 400 adequately distinguished culprit segments causing ST-segment elevation MI from control segments consisting of lipid-free autopsy specimen, which provided a sensitivity of $85 \%$ and specificity of $98 \%$. This threshold of maxLCBI $4 m m>400$ was also confirmed for nonST-segment elevation ACS (NSTE-ACS), providing a sensitivity of $64 \%$ and specificity of $94 \%$ in patients with nonST-segment elevation MI and 39\% and 90\% respectively in patients with unstable angina [35].

Accordingly, a prospective study by Madder et al. [67] in 121 patients confirmed that the presence of lipid-rich plaques with maxLCBI $\mathrm{Hmm}_{4 \mathrm{~m}}>400$ caused a 10 -fold higher risk for MACE than plaques with maxLCBI $\mathrm{m}_{4 m m}<400$. Later, the LRP study, published in 2019, studied this on a large scale in a total of 1563 patients with suspected coronary artery disease [33]. All patients underwent 3-vessel IVUS-NIRS and patients with $\operatorname{maxLCBI}{ }_{4 m m}>250$ plus a random subset of patients with maxLCBI $4 m m<250$ underwent clinical follow-up for 24 months. On a patientlevel, it was found that the presence of $\operatorname{maxLCBI} \mathrm{Lmm}_{4 \mathrm{~m}}>400$
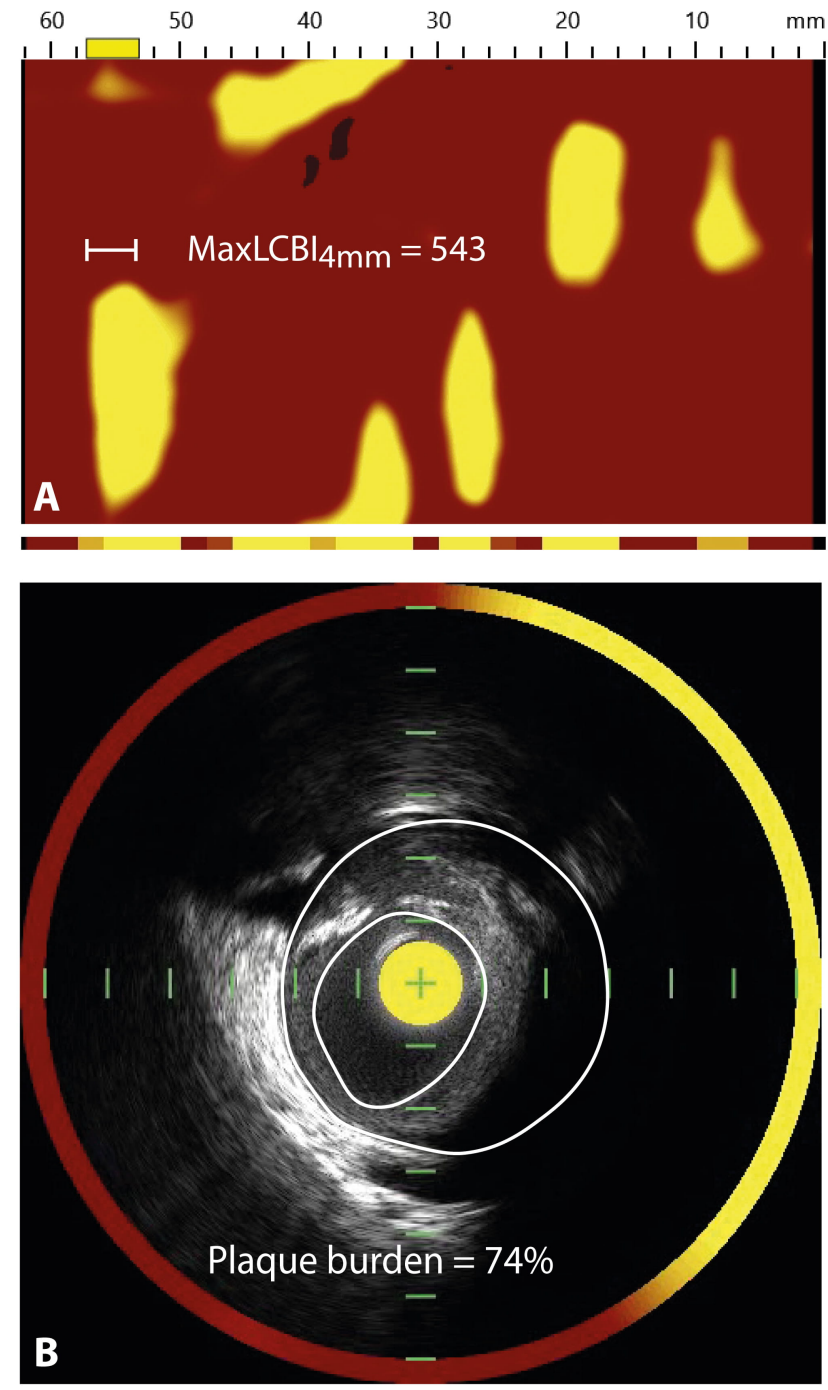

Fig. 4. Lipid-rich plaque on intravascular ultrasound with near-infrared spectroscopy. (A) demonstrates the chemogram as obtained with NIRS pullback. This is a chemical map of the coronary artery, with the most distal part of the pullback on the right and the proximal part on the left. All pixels that demonstrate a probability of $>60 \%$ to contain lipid, based on autopsy studies, will shift from red to yellow. The LCBI is then calculated as the amount of yellow pixels in the chemogram, or per region of interest (e.g., per $4 \mathrm{~mm}$ ). The $\operatorname{maxLCBI}_{4 \mathrm{~mm}}$ in this patient is 543 , i.e., more than 400 , demonstrating the presence of a lipid-rich plaque at $\sim 55 \mathrm{~mm}$ of the pullback. In (B), the IVUS cross-section of the left anterior descending artery at the location of the lipidrich plaque demonstrates a structural overview of the corresponding part within the coronary artery. An echolucent (i.e., "dark") area is present, indicating the presence of lipid. The plaque burden, calculated as (total vessel area - lumen area) / total vessel area $\times 100 \%$ is $74 \%$ in this patient.

was associated with a 2-fold increased risk for non-culprit MACE, and plaque-level analysis found that segments with maxLCBI $4 m m>400$ were associated with a 3-fold in- 

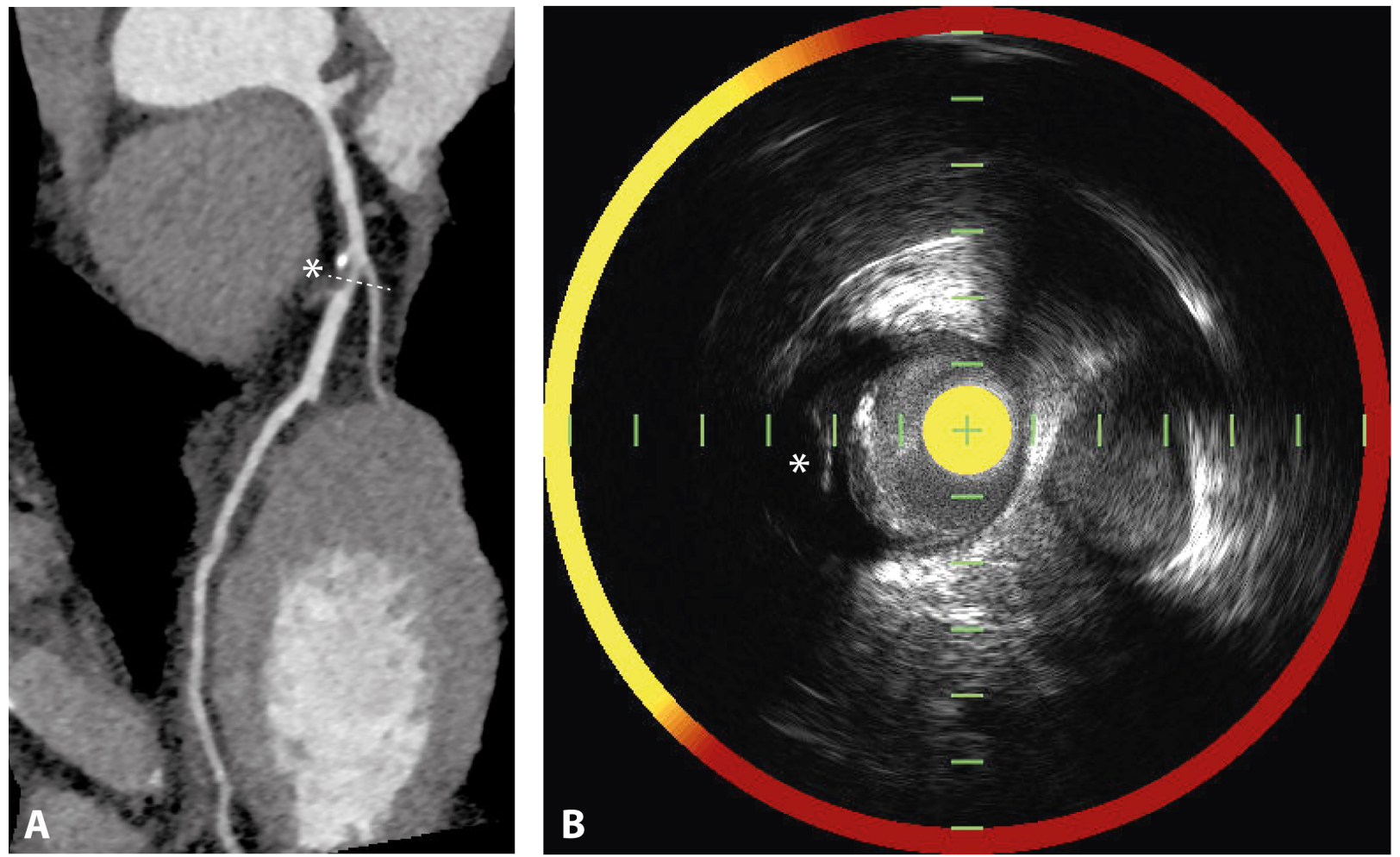

Fig. 5. Vulnerable plaque on computed tomography coronary angiography. (A) demonstrates the left anterior descending artery on CTCA. A non-calcified lipid plaque in the mid-section of the artery, around the origin of the first diagonal branch, is indicated by the asterisk. In (B) the corresponding cross-section of the left anterior descending artery and side branch on IVUS-NIRS is displayed. The non-calcified plaque appears echolucent on IVUS (indicated by the asterisk) and the yellow NIRS signal (the surrounding circle) indicates that the plaque is lipid-rich.

creased risk for non-culprit MACE. In the PROSPECT II study, the cut-off value for lipid-rich plaques was based on the highest percentile of maxLCBI ${ }_{4 m m}$ in the total cohort, which corresponded with 324.7 [28]. This threshold yielded an adjusted odds ratio of 2.3 on patient-level for future non-culprit MACE. It was suggested by the authors that the definition for vulnerable plaques should consist of a plaque burden of $\geq 70 \%$ and (optionally) a minimal luminal area of $\leq 4.0 \mathrm{~mm}^{2}$, both measured with IVUS, together with a $\operatorname{maxLCBI}{ }_{4 m m}$ of $>325$. Lowering the maxLCBI ${ }_{4 m m}$ threshold from 400 to 325 could increase the specificity to detect vulnerable plaques, but comes with reduced sensitivity.

\subsection{Non-invasive imaging techniques to detect lipid-rich plaques}

Apart from these aforementioned intracoronary imaging techniques, several non-invasive imaging techniques exist that could identify vulnerable plaque characteristics.

\subsubsection{Coronary angiography computed tomography}

A widely available non-invasive imaging technique to visualize coronary artery disease (CAD) is computed tomography coronary angiography (CTCA). CTCA has a very high diagnostic accuracy to detect coronary stenosis in patients without previously known CAD with a sensitivity of $95-99 \%$ and a specificity of $64-83 \%$ [68,69]. Moreover, CTCA may be used to assess plaque morphology to visualize non-stenotic coronary plaques $[48,49]$. The plaque density as assessed on CTCA with Hounsfield Units (HU) has been found to correspond well with echogenicity on IVUS, enabling CTCA to differentiate between the different plaque types [70], Fig. 5. Plaques that are scored as soft plaques with necrotic cores based on echogenicity of IVUS typically appear with low attenuation on CTCA $(\mathrm{HU}<30)$, while calcified plaques appear with high HU (HU around 500). Apart from the density of coronary plaques, also the attenuation pattern may be of additional information to further classify high-risk plaques. Studies have found that the addition of analysis of the so-called "napkin-ring sign", i.e., low CT attenuation in the center of the plaque but with a rim area of higher attenuation, could increase the diagnostic accuracy of CTCA to identify high-risk plaques [71,72]. It is believed that the presence of this napkin-ring sign corresponds with the OCT features of TCFA [73].

Other lesion features apart from plaque morphology that can be visualized with CTCA include vessel remodeling. IVUS-based studies found that high-risk plaques that cause ACS often show positive, i.e., outward, remodeling of the coronary artery at the lesion site [50]. This IVUS fea- 
ture can also be visualized with CTCA and the finding has been associated with ACS [51,52]. Additionally, perivascular adipose tissue can be visualized using CTCA, which can be used as a biomarker for coronary inflammation and thus identify inflamed, vulnerable atherosclerotic plaques [74].

\subsubsection{Cardiovascular magnetic resonance imaging}

Cardiovascular magnetic resonance (CMR) imaging is often used in cardiovascular medicine to evaluate structural heart disease. CMR is not frequently used in coronary plaque analysis, but it has been used to classify atherosclerotic plaques in the carotid arteries [75]. Therefore, studies have explored the utilization of CMR as a diagnostic tool to identify vulnerable coronary plaques. Károlyi et al. [37] analyzed 28 plaques of donor hearts with CMR with proven CAD. The authors classified lipid-rich plaques as those that appear hypointense on the T2-weighted CMR images, calcified plaques as those with hypointense areas on T1-weighted images, but not on the ultrashort echo time images, and fibrotic plaques as isointense regions on all sequences. This classification system was adapted from that of the carotid artery classification. These CMR classified plaques were then correlated with histopathological findings and it was demonstrated that CMR could adequately distinguish calcified plaques (sensitivity $100 \%$ and specificity 90\%) and lipid-rich plaques (sensitivity $90 \%$ and specificity $75 \%$ ), suggesting that CMR could be an additional diagnostic tool for coronary plaque analysis.

On a larger scale, Noguchi et al. [76] examined a total of almost 600 patients that had suspected or known CAD who underwent CMR (without contrast) to investigate whether T1-weighted imaging could identify high-risk coronary plaques that cause future events. The plaque-tomyocardium signal intensity was identified as the most important predictor for future coronary events. This signal intensity ratio itself is incrementally associated with highrisk plaque morphology [77]. Noguchi et al. [76] used a cut-off value of $\geq 1.4$ to identify high-intensity plaques and found that those plaques had a 4-fold higher risk for coronary events than plaques with lower signal intensity.

\subsubsection{Nuclear imaging}

Nuclear imaging using radioactive tracers containing a ${ }^{18} \mathrm{~F}$-fluoride isotope, such as ${ }^{18} \mathrm{~F}$-fluorodeoxyglucose $\left({ }^{18} \mathrm{~F}\right.$ FDG), or a Technetium-99m isotope can be used to visualize myocardial perfusion and metabolic activity [78,79]. To investigate the inflammation and lipid infiltration that are associated with vulnerable plaque morphology, nuclear molecular imaging may be of additional use. Several pathological processes that occur in vulnerable plaques can be targeted for imaging, such as inflammation and (micro)calcifications $[39,40]$. In a prospective clinical trial, Joshi et al. [80] performed ${ }^{18} \mathrm{~F}$-fluoride positron emission tomography (PET) imaging on 40 patients with $\mathrm{MI}$ and 40 patients with stable CAD and corresponded the findings with IVUS and histology. High uptake of ${ }^{18} \mathrm{~F}$ fluoride was found in plaques that had high-risk features on IVUS, such as positive remodeling and necrotic core. A limitation of nuclear imaging of the coronary arteries is that is often obscured by the tracer uptake of the myocardium, which in the study of Joshi et al. [80] was mainly seen with ${ }^{18} \mathrm{~F}$-FDG but not with ${ }^{18} \mathrm{~F}$-sodium fluoride $\left({ }^{18} \mathrm{~F}-\mathrm{NaF}\right) .{ }^{18} \mathrm{~F}-\mathrm{NaF}$ has the additional advantage that microcalcifications can be visualized, that - unlike the macrocalcifications as seen on CTCA — are associated with coronary plaque progression and vulnerable plaque formation [45]. ${ }^{18} \mathrm{~F}-\mathrm{NaF}$ PET imaging has therefore been the subject of ongoing research to guide treatment strategies, such as the PREFFIR study (ClinicalTrials.gov, identifier NCT02278211) and the EVOLVE study (ClinicalTrials.gov, identifier NCT03689946).

Another nuclear imaging modality is single positron emission computed tomography (SPECT). There has been a report of the use of SPECT to identify vulnerable plaques with TCFA-like features, mostly focusing on the detection of neovascularization, but evidence for a diagnostic value of SPECT in the vulnerable plaque analysis is limited [81].

\section{Treatment of the lipid-rich plaque}

\subsection{Systemic treatment}

\subsubsection{Lipid lowering drugs}

Current guidelines recommend lipid-lowering treatment in patients with established coronary artery disease irrespective of low-density lipoprotein (LDL) cholesterol [82]. The abovementioned technological advances in coronary imaging, including the ability to quantify plaque burden, have enabled evaluation of the recommended lipidlowering treatment. The ASTEROID investigators demonstrated that two years of statin treatment did not only reduced LDL cholesterol, but also led to regression of plaque burden measured by quantitative coronary angiography [83]. Multiple studies using serial IVUS imaging have later reaffirmed that statin therapy can slow disease progression and even promotes plaque regression in a dose-response manner [84-86].

Novel imaging modalities have also sparked interest in the effects of lipid-lowering treatment on plaque composition, looking beyond mere plaque burden or size to the role of macrophage infiltration (inflammation) and fibrous cap thickness. In the early 2000's, Crisby et al. [87] demonstrated that statin therapy effects plaque composition. Carotid plaques obtained during endarterectomy from statin-treated patients showed a lower lipid burden and less inflammatory material compared to carotid plaques from non-statin-treated patients, suggesting a plaque stabilizing effect of statin treatment. Other studies have later reiterated that the anti-inflammatory properties of statin therapy can positively impact plaque stability $[88,89]$. Multiple studies have also demonstrated that statin treatment can thicken 
and harden (by calcification) the fibrous cap of lipid-rich plaques, making these plaques less prone for rupture [9094].

In patients who do not reach their treatment goal with the maximum tolerated dose of statin, a cholesterol absorption inhibitor (ezetimibe) or a proprotein convertase subtilisin kexin type 9 (PCSK9) inhibitor on top of statin treatment should be considered [82]. Clinical trials have shown the positive effect of ezetimibe on cardiovascular outcomes in certain subgroups, but data on the effect of ezetimibe on lipid-rich plaques is limited $[95,96]$. PCSK9 inhibitors have also demonstrated to effectively decrease LDL cholesterol levels and prevent adverse cardiovascular events in clinical trial and real-world populations [97-99]. In statintreated patients, additional use of PCKS9 inhibitors induced plaque regression measured by IVUS-imaging in a greater percentage of patients compared to placebo [100]. Until recently, it remained unclear if administration of PCSK9 inhibitors also effects plaque composition in statin-treated patients [101]. During the ESC Congress 2021 the first results of the HUYGENS study (ClinicalTrials.gov, identifier NCT03570697) were presented. HUYGENS assessed whether intensified lipid lowering treatment with PCSK9 inhibitors on top of the maximally tolerated statins effected the high-risk features of lipid-rich plaques in 161 patients with non-ST-segment elevation ACS [102]. In total, 135 patients completed repeated OCT imaging after 12 months of treatment with either a PCSK9 inhibitor (evolocumab) or placebo. More intensive lipid-lowering using a PCKS9 inhibitor resulted in an increase of the minimum fibrous cap thickness and a decrease in the maximum lipid arc. At 12 months, only one in eight patients treated with a PCSK9 inhibitor in addition to the maximally tolerated statin dose had a fibrous cap thickness of $<65 \mu \mathrm{m}$, a feature associated with a high risk of plaque rupture. Again, the degree of lipid-lowering was proportional to the observed beneficiary effects.

\subsubsection{Anti-inflammatory drugs}

Accumulation of cholesterol within the vessel wall induces inflammation by activating the innate immune response and is associated with plaque instability [103]. Therefore, systemic treatment with anti-inflammatory agents might be beneficiary in patients with coronary artery disease. In recent years especially the use of colchicine, an anti-inflammatory agent previously only used for conditions such as pericarditis and gout, has received considerable interest [104,105]. Observational studies had already demonstrated that the use of colchicine was associated with a lower prevalence of $\mathrm{MI}$ in patients receiving colchicine for inflammatory conditions [106-108]. The open-label LoDoCo trial was the first randomized controlled trial evaluating the effect of low-dose colchicine ( $0.5 \mathrm{mg}$ once daily) in addition to standard secondary prevention therapies on a composite endpoint of ACS, out-of-hospital cardiac arrest and ischemic stroke in patients with CCS $(n=532)$ [104]. Colchicine use drastically reduced the primary outcome (hazard ratio $0.33 ; 95 \%$ CI $0.18-0.59 ; p<0.001$ ) and was generally well tolerated, although $11 \%$ of patients assigned to colchicine withdrew within 30 days due to perceived intestinal intolerance [104]. Subsequently, the double-blind LoDoCo 2 trial was performed to confirm whether lowdose colchicine use prevented cardiovascular events in patients with chronic coronary disease. A total of 5522 patients underwent randomization and were followed for a median duration of 28.6 months. The composite endpoint of cardiovascular death, spontaneous MI, ischemic stroke or ischemia-driven coronary revascularization occurred in $6.8 \%$ of colchicine-treated patients and in $9.6 \%$ of placebotreated patients (hazard ratio $0.69,95 \%$ CI $0.57-0.83 ; p$ $<0.001)$. Hence, the use of low-dose colchicine may now be considered in secondary prevention of cardiovascular disease, particularly if other risk factors are insufficiently controlled or if recurrent events occur under optimal therapy according to the 2021 ESC Guidelines on cardiovascular disease prevention in clinical practice [109]. In 2017, the CANTOS investigators demonstrated that the anti-inflammatory drug canakinumab, a monoclonal antibody targeting interleukin- $1 \beta$, led to a significantly lower rate of recurrent cardiovascular events at a dose of $150 \mathrm{mg}$ every 3 months, but was also associated with a higher incidence of fatal infection compared to placebo [110]. Other anti-inflammatory agents, such as lipoprotein-associated phospholipase A2 inhibitors or low-dose methotrexate, are currently not recommended for secondary prevention due to uncertain efficacy or their unfavorable risk profile [111$113]$.

\subsection{Local treatment}

Despite these aforementioned effects of systemic treatment on stabilization of lipid-rich plaques, it appears that solely a strict systemic lipid-lowering regime and even adding an anti-inflammatory agent might not be enough. Patients on intensive statin therapy, according to treatment allocation in the PROVE IT TIMI 22 trial, had a residual risk for cardiovascular events of roughly $20 \%$ during 2 years follow-up [114]. This stresses the need for an additional, more local treatment of vulnerable plaques.

The recently published PROSPECT ABSORB trial explored local treatment of vulnerable plaques by stenting with a bioresorbable vascular scaffold (BVS) [64]. The rationale of this study was based on a previous study where OCT images were assessed after BVS or bare-metal stent implantation of TCFAs and a potential beneficial effect on plaque stabilization was suggested since neo-intimal tissue development was observed after short- and mid-term follow-up [115]. The idea was that this would lead to thickening of the fibrous cap overlying the lipid pool and a decrease of wall shear stress, resulting in a reduction of plaque rupture or erosion. BVS was considered to be able to ob- 
Table 2. Treatment strategies to reduce plaque vulnerability.

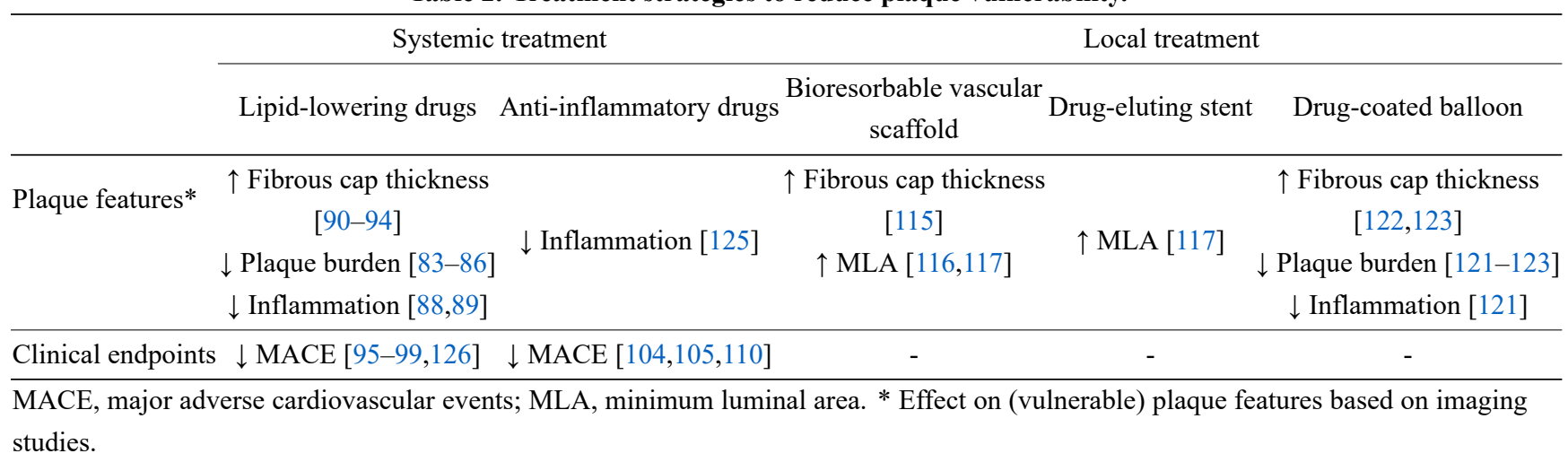

tain similar neointimal response and shear stress reduction as DES [116,117]. It was preferred over DES since it was observed that the neointimal response caused by BVS led to smaller compromise of the coronary lumen than with baremetal stent, plus it would overcome the placement of a permanent stent [115]. The PROSPECT II study, as discussed above, enrolled almost 900 patients with ACS to perform 3-vessel IVUS-NIRS after treatment of every flow-limiting stenosis [28]. All patients that had non-obstructive plaques with a plaque burden greater than $65 \%$ on IVUS, the study definition for vulnerable plaque, in the PROSPECT II study were included in the PROSPECT ABSORB trial and randomized to medical therapy or BVS treatment of the identified vulnerable plaque [64]. Randomized patients underwent follow-up angiography after 25 months with repeat IVUS-NIRS and it was found that the minimum luminal area was greater in patients treated with BVS $\left(7 \mathrm{~mm}^{2}\right.$ versus $3 \mathrm{~mm}^{2}, p<0.0001$ ) and that the lipid burden, as measured with NIRS, was significantly reduced (lipid burden $6 \%$ versus $27 \%, p<0.0001 ; \operatorname{maxLCBI}_{4 m m} 62$ versus 269 , $p<0.0001)$. Thus, revascularization with BVS seemed effective in the reduction of the lipid burden. But since the study was not powered for clinical endpoints, an effect on target lesion failure could not be confirmed. The prematurely-halted PECTUS study had a similar trial design to the PROSPECT ABSORB study, although the chosen intracoronary imaging modality was OCT [118]. The study was halted when the ABSORB stent was removed from the market. Although no definite conclusions could be drawn from the 34 patients that had been randomized between BVS or optimal medical therapy by the time of termination of the study, no differences in the primary endpoint of target-lesion failure were observed between the randomization groups. The PREVENT study (Clinicaltrials.gov, identifier NCT02316886) is currently ongoing and aims to include 1600 participants with both ACS and CCS to investigate treatment of vulnerable plaques with either BVS or DES versus optimal medical therapy alone.

A major concern of local treatment of a lipid-rich plaque is the risk for distal embolization of the lipid pool and potential periprocedural MI $[119,120]$. However, no procedural MI occurred in the entire PROSPECT ABSORB trial, and the primary safety endpoint of target-lesion failure (consisting of cardiac death, target-vessel related MI or target-lesion revascularization) was equal between randomization groups.

Still, implantation of a stent or scaffold in non-flowlimiting, thus non-ischemic, plaques could introduce potential harms of a new, stent-related "disease" such as stent thrombosis or in-stent restenosis that would otherwise not occur. Therefore, the DEBuT-LRP study (ClinicalTrials.gov, identifier NCT04765956) is currently investigating the safety and efficacy of treatment of lipid-rich plaques with a drug-coated balloon (DCB). An animal study demonstrated that in cholesterol-fed rabbits with balloon-injuryinduced lesions in the aorta, angioplasty with a paclitaxelcoated balloon led to a higher reduction of inflammation and plaque burden than plain balloon angioplasty [121]. Human studies confirmed that DCB treatment led to plaque burden reduction and even an increase of the fibrous cap thickness [122,123]. Thus DCBs are a proven alternative to stenting for several indications, but could now also play a role in the treatment of lipid-rich plaques [124]. The DEBuT-LRP study aims to enroll 40 patients with NSTEACS that will subsequently undergo 3-vessel IVUS-NIRS and a lipid-rich plaque (i.e., $\operatorname{maxLCBI} \mathrm{Cmm}_{4 \mathrm{~m}}>400$ ) will be treated with DCB. DCB-treated patients will undergo follow-up angiography after 9 months with repeat IVUSNIRS for the primary endpoint of $\operatorname{maxLCBI} \mathrm{Cm}_{4 \mathrm{~m}}$ reduction of the treated LRP. If proven effective, the DCB may be a safe alternative to stenting in the treatment of a lipidrich plaque. Table 2 (Ref. [83-86,88,99,104,105,110,115117,121-123,125,126]) summarizes the effects of different treatment strategies on vulnerable plaque features.

\section{Conclusions}

ACS mostly arises from rupture or erosion of a vulnerable plaque. Vulnerable plaques typically appear as lipidrich plaques with a thin cap, called TCFA. These vulnerable plaques can be detected using intracoronary imaging and possibly also with non-invasive imaging techniques. Currently, the implantation of a stent or scaffold for the treat- 
ment of vulnerable plaques has been found to be safe and to stabilize high-risk plaque features. Future studies should focus on optimizing imaging techniques and evaluating the effectiveness of vulnerable plaque stabilization on clinical endpoints.

\section{Author contributions}

$\mathrm{AvV}$ and NMRvdS wrote the manuscript with support from JPSH and BEPMC. All authors read and approved the final manuscript.

\section{Ethics approval and consent to participate}

Not applicable.

\section{Acknowledgment}

Thanks to all the peer reviewers for their opinions and suggestions.

\section{Funding}

This research received no external funding.

\section{Conflict of interest}

The authors declare no conflict of interest.

\section{References}

[1] Hartzler GO, Rutherford BD, McConahay DR. Percutaneous transluminal coronary angioplasty: Application for acute myocardial infarction. The American Journal of Cardiology. 1984; 53: C117-C121.

[2] Keeley EC, Boura JA, Grines CL. Primary angioplasty versus intravenous thrombolytic therapy for acute myocardial infarction: a quantitative review of 23 randomised trials. The Lancet. 2003; 361: 13-20.

[3] Sanchis-Gomar F, Perez-Quilis C, Leischik R, Lucia A. Epidemiology of coronary heart disease and acute coronary syndrome. Annals of Translational Medicine. 2016; 4: 256.

[4] Kolansky DM. Acute coronary syndromes: morbidity, mortality, and pharmacoeconomic burden. The American Journal of Managed Care 2009; 15: S36-S41.

[5] Cutlip DE, Chhabra AG, Baim DS, Chauhan MS, Marulkar S, Massaro J, et al. Beyond restenosis: five-year clinical outcomes from second-generation coronary stent trials. Circulation. 2004; 110: $1226-1230$.

[6] Muller JE, Tofler GH, Stone PH. Circadian variation and triggers of onset of acute cardiovascular disease. Circulation. 1989; 79: 733-743.

[7] Brown BG, Gallery CA, Badger RS, Kennedy JW, Mathey D, Bolson EL, et al. Incomplete lysis of thrombus in the moderate underlying atherosclerotic lesion during intracoronary infusion of streptokinase for acute myocardial infarction: quantitative angiographic observations. Circulation. 1986; 73: 653-661.

[8] Little WC, Constantinescu M, Applegate RJ, Kutcher MA, Burrows MT, Kahl FR, et al. Can coronary angiography predict the site of a subsequent myocardial infarction in patients with mild-to-moderate coronary artery disease? Circulation. 1988; 78: 1157-1166.

[9] Naghavi M, Libby P, Falk E, Casscells SW, Litovsky S, Rumberger $\mathrm{J}$, et al. From vulnerable plaque to vulnerable patient: a call for new definitions and risk assessment strategies: Part I. Circulation. 2003; 108: 1664-1672.
[10] Naghavi M, Libby P, Falk E, Casscells SW, Litovsky S, Rumberger J, et al. From vulnerable plaque to vulnerable patient: a call for new definitions and risk assessment strategies: Part II. Circulation. 2003; 108: 1772-1778.

[11] Al-Lamee R, Mintz GS. What are the PROSPECTs and clinical implications of vulnerable plaque? European Heart Journal. 2021; 42: 4680-4682.

[12] DeWood MA, Spores J, Notske R, Mouser LT, Burroughs R, Golden MS, et al. Prevalence of total coronary occlusion during the early hours of transmural myocardial infarction. The New England Journal of Medicine. 1980; 303: 897-902.

[13] Falk E, Shah PK, Fuster V. Coronary plaque disruption. Circulation. 1995; 92: 657-671.

[14] Ambrose JA, Tannenbaum MA, Alexopoulos D, HjemdahlMonsen CE, Leavy J, Weiss M, et al. Angiographic progression of coronary artery disease and the development of myocardial infarction. Journal of the American College of Cardiology. 1988; 12: $56-62$

[15] Glaser R, Selzer F, Faxon DP, Laskey WK, Cohen HA, Slater $\mathrm{J}$, et al. Clinical progression of incidental, asymptomatic lesions discovered during culprit vessel coronary intervention. Circulation. 2005; 111: 143-149.

[16] Giroud D, Li JM, Urban P, Meier B, Rutishauer W. Relation of the site of acute myocardial infarction to the most severe coronary arterial stenosis at prior angiography. The American Journal of Cardiology. 1992; 69: 729-732.

[17] Libby P. Molecular Bases of the Acute Coronary Syndromes. Circulation. 1995; 91: 2844-2850.

[18] Zarins CK, Giddens DP, Bharadvaj BK, Sottiurai VS, Mabon RF, Glagov S. Carotid bifurcation atherosclerosis. Quantitative correlation of plaque localization with flow velocity profiles and wall shear stress. Circulation Research. 1983; 53: 502-514.

[19] Badimon L, Vilahur G. Thrombosis formation on atherosclerotic lesions and plaque rupture. Journal of Internal Medicine. 2014; 276: 618-632.

[20] Tang D, Teng Z, Canton G, Hatsukami TS, Dong L, Huang $\mathrm{X}$, et al. Local critical stress correlates better than global maximum stress with plaque morphological features linked to atherosclerotic plaque vulnerability: an in vivo multi-patient study. BioMedical Engineering OnLine. 2009; 8: 15.

[21] Slager CJ, Wentzel JJ, Gijsen FJH, Schuurbiers JCH, van der Wal AC, van der Steen AFW, et al. The role of shear stress in the generation of rupture-prone vulnerable plaques. Nature Clinical Practice Cardiovascular Medicine. 2005; 2: 401-407.

[22] Burke AP, Farb A, Malcom GT, Liang YH, Smialek J, Virmani R. Coronary risk factors and plaque morphology in men with coronary disease who died suddenly. The New England Journal of Medicine. 1997; 336: 1276-1282.

[23] Kolodgie FD, Burke AP, Farb A, Gold HK, Yuan J, Narula J, et al. The thin-cap fibroatheroma: a type of vulnerable plaque: the major precursor lesion to acute coronary syndromes. Current Opinion in Cardiology. 2001; 16: 285-292.

[24] Virmani R, Kolodgie FD, Burke AP, Farb A, Schwartz SM. Lessons from sudden coronary death: a comprehensive morphological classification scheme for atherosclerotic lesions. Arteriosclerosis, Thrombosis, and Vascular Biology. 2000; 20: $1262-1275$.

[25] Stary HC, Chandler AB, Glagov S, Guyton JR, Insull W, Rosenfeld ME, et al. A definition of initial, fatty streak, and intermediate lesions of atherosclerosis. a report from the Committee on Vascular Lesions of the Council on Arteriosclerosis, American Heart Association. Arteriosclerosis and Thrombosis. 1994; 14: 840-856.

[26] Stary HC, Chandler AB, Dinsmore RE, Fuster V, Glagov S, Insull $\mathrm{W}$, et al. A definition of advanced types of atherosclerotic lesions and a histological classification of atherosclerosis. a re- 
port from the Committee on Vascular Lesions of the Council on Arteriosclerosis, American Heart Association. Arteriosclerosis, Thrombosis, and Vascular Biology. 1995; 15: 1512-1531.

[27] Stone GW, Maehara A, Lansky AJ, de Bruyne B, Cristea E, Mintz GS, et al. A prospective natural-history study of coronary atherosclerosis. The New England Journal of Medicine. 2011; 364: 226-235.

[28] Erlinge D, Maehara A, Ben-Yehuda O, Bøtker HE, Maeng M, Kjøller-Hansen L, et al. Identification of vulnerable plaques and patients by intracoronary near-infrared spectroscopy and ultrasound (PROSPECT II): a prospective natural history study. The Lancet. 2021; 397: 985-995.

[29] Kume T, Akasaka T, Kawamoto T, Okura H, Watanabe N, Toyota $\mathrm{E}$, et al. Measurement of the thickness of the fibrous cap by optical coherence tomography. American Heart Journal. 2006; 152: 755.e1-755.e4.

[30] Tobis JM, Mallery J, Mahon D, Lehmann K, Zalesky P, Griffith $\mathrm{J}$, et al. Intravascular ultrasound imaging of human coronary arteries in vivo. Analysis of tissue characterizations with comparison to in vitro histological specimens. Circulation. 1991; 83: 913-926.

[31] Gussenhoven EJ, Essed CE, Lancée CT, Mastik F, Frietman P, van Egmond FC, et al. Arterial wall characteristics determined by intravascular ultrasound imaging: an in vitro study. Journal of the American College of Cardiology. 1989; 14: 947-952.

[32] Allen TJ, Hall A, Dhillon AP, Owen JS, Beard PC. Spectroscopic photoacoustic imaging of lipid-rich plaques in the human aorta in the 740 to $1400 \mathrm{~nm}$ wavelength range. Journal of Biomedical Optics. 2012; 17: 061209.

[33] Waksman R, Di Mario C, Torguson R, Ali ZA, Singh V, Skinner $\mathrm{WH}$, et al. Identification of patients and plaques vulnerable to future coronary events with near-infrared spectroscopy intravascular ultrasound imaging: a prospective, cohort study. The Lancet. 2019; 394: 1629-1637.

[34] Madder RD, Goldstein JA, Madden SP, Puri R, Wolski K, Hendricks $\mathrm{M}$, et al. Detection by near-infrared spectroscopy of large lipid core plaques at culprit sites in patients with acute STsegment elevation myocardial infarction. JACC: Cardiovascular Interventions. 2013; 6: 838-846.

[35] Madder RD, Husaini M, Davis AT, VanOosterhout S, Harnek $\mathrm{J}$, Götberg M, et al. Detection by near-infrared spectroscopy of large lipid cores at culprit sites in patients with non-ST-segment elevation myocardial infarction and unstable angina. Catheterization and Cardiovascular Interventions. 2015; 86: 1014-1021.

[36] Gardner CM, Tan H, Hull EL, Lisauskas JB, Sum ST, Meese TM, et al. Detection of Lipid Core Coronary Plaques in Autopsy Specimens with a Novel Catheter-Based near-Infrared Spectroscopy System. JACC: Cardiovascular Imaging. 2008; 1: 638648.

[37] Károlyi M, Seifarth H, Liew G, Schlett CL, Maurovich-Horvat $\mathrm{P}$, Stolzmann P, et al. Classification of Coronary Atherosclerotic Plaques Ex Vivo with T1, T2, and Ultrashort Echo Time CMR. JACC: Cardiovascular Imaging. 2013; 6: 466-474.

[38] Di Vito L, Agozzino M, Marco V, Ricciardi A, Concardi M, Romagnoli E, et al. Identification and quantification of macrophage presence in coronary atherosclerotic plaques by optical coherence tomography. European Heart Journal Cardiovascular Imaging. 2015; 16: 807-813.

[39] Lee SJ, Paeng JC. Nuclear Molecular Imaging for Vulnerable Atherosclerotic Plaques. Korean Journal of Radiology. 2015; 16: 955-966.

[40] Tawakol A, Migrino RQ, Bashian GG, Bedri S, Vermylen D, Cury RC, et al. In vivo $18 \mathrm{~F}$-fluorodeoxyglucose positron emission tomography imaging provides a noninvasive measure of carotid plaque inflammation in patients. Journal of the American College of Cardiology. 2006; 48: 1818-1824.
[41] Dong L, Mintz GS, Witzenbichler B, Metzger DC, Rinaldi MJ, Duffy PL, et al. Comparison of plaque characteristics in narrowings with ST-elevation myocardial infarction (STEMI), nonSTEMI/unstable angina pectoris and stable coronary artery disease (from the ADAPT-DES IVUS Substudy). The American Journal of Cardiology. 2015; 115: 860-866.

[42] Iqbal SN, Feit F, Mancini GBJ, Wood D, Patel R, Pena-Sing I, et al. Characteristics of plaque disruption by intravascular ultrasound in women presenting with myocardial infarction without obstructive coronary artery disease. American Heart Journal. 2014; 167: 715-722.

[43] Sugiyama T, Yamamoto E, Bryniarski K, Xing L, Lee H, Isobe $\mathrm{M}$, et al. Nonculprit Plaque Characteristics in Patients with Acute Coronary Syndrome Caused by Plaque Erosion vs Plaque Rupture: a 3-Vessel Optical Coherence Tomography Study. JAMA Cardiology. 2018; 3: 207-214.

[44] Krishnamoorthy P, Vengrenyuk Y, Ueda H, Yoshimura T, Pena $\mathrm{J}$, Motoyama S, et al. Three-dimensional volumetric assessment of coronary artery calcification in patients with stable coronary artery disease by OCT. EuroIntervention. 2017; 13: 312-319.

[45] Creager MD, Hohl T, Hutcheson JD, Moss AJ, Schlotter F, Blaser MC, et al. 18F-Fluoride Signal Amplification Identifies Microcalcifications Associated with Atherosclerotic Plaque Instability in Positron Emission Tomography/Computed Tomography Images. Circulation: Cardiovascular Imaging. 2019; 12: e007835.

[46] Di Mario C, Görge G, Peters R, Kearney P, Pinto F, Hausmann $\mathrm{D}$, et al. Clinical application and image interpretation in intracoronary ultrasound. Study Group on Intracoronary Imaging of the Working Group of Coronary Circulation and of the Subgroup on Intravascular Ultrasound of the Working Group of Echocardiography of the European Society of Cardiology. European Heart Journal. 1998; 19: 207-229.

[47] Gerbaud E, Weisz G, Tanaka A, Luu R, Osman HASH, Baldwin $\mathrm{G}$, et al. Plaque burden can be assessed using intravascular optical coherence tomography and a dedicated automated processing algorithm: a comparison study with intravascular ultrasound. European Heart Journal - Cardiovascular Imaging. 2020; 21: 640-652.

[48] Park H, Heo R, Ó Hartaigh B, Cho I, Gransar H, Nakazato R, et al. Atherosclerotic plaque characteristics by $\mathrm{CT}$ angiography identify coronary lesions that cause ischemia: a direct comparison to fractional flow reserve. JACC: Cardiovascular Imaging. 2015; 8: 1-10.

[49] Versteylen MO, Kietselaer BL, Dagnelie PC, Joosen IA, Dedic A, Raaijmakers RH, et al. Additive value of semiautomated quantification of coronary artery disease using cardiac computed tomographic angiography to predict future acute coronary syndrome. Journal of the American College of Cardiology. 2013; 61: 2296-2305.

[50] Schoenhagen P, Ziada KM, Kapadia SR, Crowe TD, Nissen SE, Tuzcu EM. Extent and direction of arterial remodeling in stable versus unstable coronary syndromes: an intravascular ultrasound study. Circulation. 2000; 101: 598-603.

[51] Narula J, Nakano M, Virmani R, Kolodgie FD, Petersen R, Newcomb R, et al. Histopathologic characteristics of atherosclerotic coronary disease and implications of the findings for the invasive and noninvasive detection of vulnerable plaques. Journal of the American College of Cardiology. 2013; 61: 1041-1051.

[52] Motoyama S, Sarai M, Harigaya H, Anno H, Inoue K, Hara T, et al. Computed Tomographic Angiography Characteristics of Atherosclerotic Plaques Subsequently Resulting in Acute Coronary Syndrome. Journal of the American College of Cardiology. 2009; 54: 49-57.

[53] Koganti S, Kotecha T, Rakhit RD. Choice of Intracoronary Imaging: when to Use Intravascular Ultrasound or Optical Co- 
herence Tomography. Interventional Cardiology Review. 2016; 11: 11 .

[54] Terashima M, Kaneda H, Suzuki T. The role of optical coherence tomography in coronary intervention. The Korean Journal of Internal Medicine. 2012; 27: 1-12.

[55] Roelandt JR, Serruys PW, Bom N, Gussenhoven WG, Lancee $\mathrm{CT}$, ten Hoff $\mathrm{H}$. Intravascular real-time, two-dimensional echocardiography. International Journal of Cardiac Imaging. 1989; 4: 63-67.

[56] Garcìa-Garcìa HM, Gogas BD, Serruys PW, Bruining N. IVUSbased imaging modalities for tissue characterization: similarities and differences. The International Journal of Cardiovascular Imaging. 2011; 27: 215-224.

[57] Low A, Kawase Y, Chan Y, Tearney G, Bouma B, Jang I. In vivo characterisation of coronary plaques with conventional greyscale intravascular ultrasound: correlation with optical coherence tomography. EuroIntervention. 2009; 4: 626-632.

[58] Calvert PA, Obaid DR, O'Sullivan M, Shapiro LM, McNab D, Densem CG, et al. Association between IVUS findings and adverse outcomes in patients with coronary artery disease: the VIVA (VH-IVUS in Vulnerable Atherosclerosis) Study. JACC: Cardiovascular Imaging. 2011; 4: 894-901.

[59] Brown AJ, Obaid DR, Costopoulos C, Parker RA, Calvert PA, Teng Z, et al. Direct Comparison of Virtual-Histology Intravascular Ultrasound and Optical Coherence Tomography Imaging for Identification of Thin-Cap Fibroatheroma. Circulation: Cardiovascular Imaging. 2015; 8: e003487.

[60] Fujii K, Hao H, Shibuya M, Imanaka T, Fukunaga M, Miki K, et al. Accuracy of OCT, grayscale IVUS, and their combination for the diagnosis of coronary TCFA: an ex vivo validation study. JACC: Cardiovascular Imaging. 2015; 8: 451-460.

[61] Tearney GJ, Jang IK, Kang DH, Aretz HT, Houser SL, Brady $\mathrm{TJ}$, et al. Porcine coronary imaging in vivo by optical coherence tomography. Acta Cardiologica. 2000; 55: 233-237.

[62] Yabushita H, Bouma BE, Houser SL, Aretz HT, Jang I, Schlendorf $\mathrm{KH}$, et al. Characterization of human atherosclerosis by optical coherence tomography. Circulation. 2002; 106: 16401645.

[63] Hau WKT, Yan BPY. Role of Intravascular Imaging in Primary PCI. Primary Angioplasty. 2018; 361: 179-195.

[64] Stone GW, Maehara A, Ali ZA, Held C, Matsumura M, KjøllerHansen L, et al. Percutaneous Coronary Intervention for Vulnerable Coronary Atherosclerotic Plaque. Journal of the American College of Cardiology. 2020; 76: 2289-2301.

[65] Ino Y, Kubo T, Kameyama T, Shimamura K, Terada K, Matsuo $\mathrm{Y}$, et al. Clinical Utility of Combined Optical Coherence Tomography and near-Infrared Spectroscopy for Assessing the Mechanism of very Late Stent Thrombosis. JACC: Cardiovascular Imaging. 2018; 11: 772-775.

[66] Fard AM, Vacas-Jacques P, Hamidi E, Wang H, Carruth RW, Gardecki JA, et al. Optical coherence tomography-near infrared spectroscopy system and catheter for intravascular imaging. Optics Express. 2013; 21: 30849-30858.

[67] Madder RD, Husaini M, Davis AT, VanOosterhout S, Khan $\mathrm{M}$, Wohns D, et al. Large lipid-rich coronary plaques detected by near-infrared spectroscopy at non-stented sites in the target artery identify patients likely to experience future major adverse cardiovascular events. European Heart Journal Cardiovascular Imaging. 2016; 17: 393-399.

[68] Meijboom WB, Meijs MFL, Schuijf JD, Cramer MJ, Mollet NR, van Mieghem CAG, et al. Diagnostic accuracy of 64-slice computed tomography coronary angiography: a prospective, multicenter, multivendor study. Journal of the American College of Cardiology. 2008; 52: 2135-2144.

[69] Abbara S. Diagnostic Performance of 64-Multidetector Row Coronary Computed Tomographic Angiography for Evaluation of Coronary Artery Stenosis in Individuals without Known Coronary Artery Disease: Results from the Prospective Multicenter ACCURACY (Assessment by Coronary Computed Tomographic Angiography of Individuals Undergoing Invasive Coronary Angiography) Trial. Yearbook of Diagnostic Radiology. 2008; 2009: 346-347.

[70] Motoyama S, Kondo T, Anno H, Sugiura A, Ito Y, Mori K, et al. Atherosclerotic plaque characterization by 0.5 -mm-slice multislice computed tomographic imaging - Comparison with intravascular ultrasound. Circulation Journal. 2007; 71: 363366.

[71] Maurovich-Horvat P, Hoffmann U, Vorpahl M, Nakano M, Virmani R, Alkadhi $\mathrm{H}$. The napkin-ring sign: CT signature of highrisk coronary plaques? JACC: Cardiovascular Imaging. 2010; 3: 440-444.

[72] Maurovich-Horvat P, Schlett CL, Alkadhi H, Nakano M, Otsuka F, Stolzmann P, et al. The Napkin-Ring Sign Indicates Advanced Atherosclerotic Lesions in Coronary CT Angiography. JACC: Cardiovascular Imaging. 2012; 5: 1243-1252.

[73] Kashiwagi M, Tanaka A, Kitabata H, Tsujioka H, Kataiwa H, Komukai K, et al. Feasibility of Noninvasive Assessment of Thin-Cap Fibroatheroma by Multidetector Computed Tomography. JACC: Cardiovascular Imaging. 2009; 2: 1412-1419.

[74] Antonopoulos AS, Sanna F, Sabharwal N, Thomas S, Oikonomou EK, Herdman L, et al. Detecting human coronary inflammation by imaging perivascular fat. Science Translational Medicine. 2017; 9: eaal2658

[75] Cai J, Hatsukami TS, Ferguson MS, Small R, Polissar NL, Yuan C. Classification of human carotid atherosclerotic lesions with in vivo multicontrast magnetic resonance imaging. Circulation. 2002; 106: 1368-1373.

[76] Noguchi T, Kawasaki T, Tanaka A, Yasuda S, Goto Y, Ishihara $\mathrm{M}$, et al. High-intensity signals in coronary plaques on noncontrast $\mathrm{T} 1$-weighted magnetic resonance imaging as a novel determinant of coronary events. Journal of the American College of Cardiology. 2014; 63: 989-999.

[77] Matsumoto K, Ehara S, Hasegawa T, Nishimura S, Shimada K. The signal intensity of coronary culprit lesions on T1-weighted magnetic resonance imaging is directly correlated with the accumulation of vulnerable morphologies. International Journal of Cardiology. 2017; 231: 284-286.

[78] Henzlova MJ, Duvall WL, Einstein AJ, Travin MI, Verberne HJ. ASNC imaging guidelines for SPECT nuclear cardiology procedures: Stress, protocols, and tracers. Journal of Nuclear Cardiology. 2016; 23: 606-639.

[79] Dilsizian V, Bacharach SL, Beanlands RS, Bergmann SR, Delbeke D, Dorbala $\mathrm{S}$, et al. ASNC imaging guidelines/SNMMI procedure standard for positron emission tomography (PET) nuclear cardiology procedures. Journal of Nuclear Cardiology. 2016; 23: 1187-1226.

[80] Joshi NV, Vesey AT, Williams MC, Shah ASV, Calvert PA, Craighead FHM, et al. 18F-fluoride positron emission tomography for identification of ruptured and high-risk coronary atherosclerotic plaques: a prospective clinical trial. The Lancet. 2014; 383: 705-713.

[81] Sun Yoo J, Lee J, Ho Jung J, Seok Moon B, Kim S, Chul Lee B, et al. SPECT/CT Imaging of High-Risk Atherosclerotic Plaques using Integrin-Binding RGD Dimer Peptides. Scientific Reports. 2015; 5: 11752.

[82] Knuuti J, Wijns W, Saraste A, Capodanno D, Barbato E, FunckBrentano C, et al. 2019 ESC Guidelines for the diagnosis and management of chronic coronary syndromes: The Task Force for the diagnosis and management of chronic coronary syndromes of the European Society of Cardiology (ESC). European heart journal 2019; 41: 407-477.

[83] Ballantyne CM, Raichlen JS, Nicholls SJ, Erbel R, Tardif J, 
Brener SJ, et al. Effect of rosuvastatin therapy on coronary artery stenoses assessed by quantitative coronary angiography: a study to evaluate the effect of rosuvastatin on intravascular ultrasound-derived coronary atheroma burden. Circulation. 2008; 117: 2458-2466.

[84] Nissen SE, Nicholls SJ, Sipahi I, Libby P, Raichlen JS, Ballantyne CM, et al. Effect of very High-Intensity Statin Therapy on Regression of Coronary Atherosclerosis. The ASTEROID Trial. The Journal of the American Medical Association. 2006; 295: 1556.

[85] Nicholls SJ, Ballantyne CM, Barter PJ, Chapman MJ, Erbel RM, Libby $\mathrm{P}$, et al. Effect of two intensive statin regimens on progression of coronary disease. The New England Journal of Medicine. 2011; 365: 2078-2087.

[86] Kawasaki M, Sano K, Okubo M, Yokoyama H, Ito Y, Murata I, et al. Volumetric Quantitative Analysis of Tissue Characteristics of Coronary Plaques after Statin Therapy Using ThreeDimensional Integrated Backscatter Intravascular Ultrasound. Journal of the American College of Cardiology. 2005; 45: 19461953.

[87] Crisby M, Nordin-Fredriksson G, Shah PK, Yano J, Zhu J, Nilsson J. Pravastatin treatment increases collagen content and decreases lipid content, inflammation, metalloproteinases, and cell death in human carotid plaques: implications for plaque stabilization. Circulation. 2001; 103: 926-933.

[88] Puri R, Nissen SE, Libby P, Shao M, Ballantyne CM, Barter $\mathrm{PJ}$, et al. C-Reactive Protein, but not Low-Density Lipoprotein Cholesterol Levels, Associate with Coronary Atheroma Regression and Cardiovascular Events after Maximally Intensive Statin Therapy. Circulation. 2013; 128: 2395-2403.

[89] Nissen SE, Tuzcu EM, Schoenhagen P, Crowe T, Sasiela WJ, Tsai J, et al. Statin Therapy, LDL Cholesterol, C-Reactive Protein, and Coronary Artery Disease. The New England Journal of Medicine. 2005; 352: 29-38.

[90] Kataoka Y, Hammadah M, Puri R, Duggal B, Uno K, Kapadia $\mathrm{SR}$, et al. Plaque microstructures in patients with coronary artery disease who achieved very low low-density lipoprotein cholesterol levels. Atherosclerosis. 2015; 242: 490-495.

[91] Komukai K, Kubo T, Kitabata H, Matsuo Y, Ozaki Y, Takarada $\mathrm{S}$, et al. Effect of atorvastatin therapy on fibrous cap thickness in coronary atherosclerotic plaque as assessed by optical coherence tomography: the EASY-FIT study. Journal of the American College of Cardiology. 2014; 64: 2207-2217.

[92] Nishio R, Shinke T, Otake H, Nakagawa M, Nagoshi R, Inoue T, et al. Stabilizing effect of combined eicosapentaenoic acid and statin therapy on coronary thin-cap fibroatheroma. Atherosclerosis. 2014; 234: 114-119.

[93] Puri R, Nicholls SJ, Shao M, Kataoka Y, Uno K, Kapadia SR, et al. Impact of statins on serial coronary calcification during atheroma progression and regression. Journal of the American College of Cardiology. 2015; 65: 1273-1282.

[94] Kataoka Y, Puri R, Hammadah M, Duggal B, Uno K, Kapadia SR, et al. Frequency-domain optical coherence tomographic analysis of plaque microstructures at nonculprit narrowings in patients receiving potent statin therapy. The American Journal of Cardiology. 2014; 114: 549-554.

[95] Baigent C, Landray MJ, Reith C, Emberson J, Wheeler DC, Tomson C, et al. The effects of lowering LDL cholesterol with simvastatin plus ezetimibe in patients with chronic kidney disease (Study of Heart and Renal Protection): a randomised placebo-controlled trial. The Lancet. 2011; 377: 2181-2192.

[96] Cannon CP, Blazing MA, Giugliano RP, McCagg A, White JA, Theroux P, et al. Ezetimibe Added to Statin Therapy after Acute Coronary Syndromes. The New England Journal of Medicine. 2015; 372: 2387-2397.

[97] Robinson JG, Farnier M, Krempf M, Bergeron J, Luc G, Av- erna M, et al. Efficacy and Safety of Alirocumab in Reducing Lipids and Cardiovascular Events. The New England Journal of Medicine. 2015; 372: 1489-1499.

[98] Sabatine MS, Giugliano RP, Keech AC, Honarpour N, Wiviott SD, Murphy SA, et al. Evolocumab and Clinical Outcomes in Patients with Cardiovascular Disease. The New England Journal of Medicine. 2017; 376: 1713-1722.

[99] Saba PS, Murgia A, Gazale E, Terrosu P, Sanna GD, Parodi G. Efficacy and safety of PCSK9-Inhibitors in the real-world: data from a clinical registry. European Heart Journal. 2020; 41

[100] Nicholls SJ, Puri R, Anderson T, Ballantyne CM, Cho L, Kastelein JJP, et al. Effect of Evolocumab on Progression of Coronary Disease in Statin-Treated Patients. The Journal of the American Medical Association. 2016; 316: 2373.

[101] Nicholls SJ, Puri R, Anderson T, Ballantyne CM, Cho L, Kastelein JJP, et al. Effect of Evolocumab on Coronary Plaque Composition. Journal of the American College of Cardiology. 2018; 72: 2012-2021.

[102] Nicholls SJ, Nissen SE, Prati F, Windecker S, Kataoka Y, Puri $\mathrm{R}$, et al. Assessing the impact of PCSK9 inhibition on coronary plaque phenotype with optical coherence tomography: rationale and design of the randomized, placebo-controlled HUYGENS study. Cardiovascular Diagnosis and Therapy. 2021; 11: 120 129.

[103] Imazio M, Nidorf M. Colchicine and the heart. European Heart Journal. 2021; 42: 2745-2760.

[104] Nidorf SM, Eikelboom JW, Budgeon CA, Thompson PL. Lowdose colchicine for secondary prevention of cardiovascular disease. Journal of the American College of Cardiology. 2013; 61: 404-410.

[105] Nidorf SM, Fiolet ATL, Mosterd A, Eikelboom JW, Schut A, Opstal TSJ, et al. Colchicine in Patients with Chronic Coronary Disease. The New England Journal of Medicine 2020; 383: $1838-1847$.

[106] Langevitz P, Livneh A, Neumann L, Buskila D, Shemer J, Amolsky D, et al. Prevalence of ischemic heart disease in patients with familial Mediterranean fever. The Israel Medical Association Journal. 2001; 3: 9-12.

[107] Crittenden DB, Lehmann RA, Schneck L, Keenan RT, Shah B, Greenberg JD, et al. Colchicine use is associated with decreased prevalence of myocardial infarction in patients with gout. The Journal of Rheumatology. 2012; 39: 1458-1464.

[108] Solomon DH, Liu C, Kuo I, Zak A, Kim SC. Effects of colchicine on risk of cardiovascular events and mortality among patients with gout: a cohort study using electronic medical records linked with Medicare claims. Annals of the Rheumatic Diseases. 2016; 75: 1674-1679.

[109] Visseren FLJ, Mach F, Smulders YM, Carballo D, Koskinas KC, Bäck M, et al. 2021 ESC Guidelines on cardiovascular disease prevention in clinical practice: Developed by the Task Force for cardiovascular disease prevention in clinical practice with representatives of the European Society of Cardiology and 12 medical societies With the special contribution of the European Association of Preventive Cardiology (EAPC). European Heart Journal. 2021; 42: 3227-3337.

[110] Ridker PM, Everett BM, Thuren T, MacFadyen JG, Chang WH, Ballantyne C, et al. Antiinflammatory Therapy with Canakinumab for Atherosclerotic Disease. The New England Journal of Medicine. 2017; 377: 1119-1131.

[111] Nicholls SJ, Kastelein JJP, Schwartz GG, Bash D, Rosenson RS, Cavender MA, et al. Varespladib and cardiovascular events in patients with an acute coronary syndrome: the VISTA-16 randomized clinical trial. The Journal of the American Medical Association. 2014; 311: 252-262.

[112] Micha R, Imamura F, Wyler von Ballmoos M, Solomon DH, Hernán MA, Ridker PM, et al. Systematic review and meta- 
analysis of methotrexate use and risk of cardiovascular disease. The American Journal of Cardiology. 2011; 108: 1362-1370.

[113] White HD, Held C, Stewart R, Tarka E, Brown R, Davies RY, et al. Darapladib for preventing ischemic events in stable coronary heart disease. The New England Journal of Medicine. 2014; 370: 1702-1711.

[114] Cannon CP, Braunwald E, McCabe CH, Rader DJ, Rouleau JL, Belder R, et al. Intensive versus moderate lipid lowering with statins after acute coronary syndromes. The New England Journal of Medicine. 2004; 350: 1495-1504.

[115] Bourantas CV, Serruys PW, Nakatani S, Zhang Y, Farooq V, Diletti $\mathrm{R}$, et al. Bioresorbable vascular scaffold treatment induces the formation of neointimal cap that seals the underlying plaque without compromising the luminal dimensions: a concept based on serial optical coherence tomography data. EuroIntervention. 2015; 11: 746-756.

[116] Bourantas CV, Papafaklis MI, Kotsia A, Farooq V, Muramatsu $\mathrm{T}$, Gomez-Lara J, et al. Effect of the endothelial shear stress patterns on neointimal proliferation following drug-eluting bioresorbable vascular scaffold implantation: an optical coherence tomography study. JACC: Cardiovascular Interventions. 2014; 7: $315-324$

[117] Gomez-Lara J, Brugaletta S, Farooq V, Onuma Y, Diletti R, Windecker S, et al. Head-to-head comparison of the neointimal response between metallic and bioresorbable everolimus-eluting scaffolds using optical coherence tomography. JACC: Cardiovascular Interventions. 2011; 4: 1271-1280.

[118] Mol J, Bom MJ, Damman P, Knaapen P, van Royen N. PreEmptive OCT-Guided Angioplasty of Vulnerable Intermediate Coronary Lesions: Results from the Prematurely Halted PECTUS-Trial. Journal of Interventional Cardiology. 2020; 2020: 8821525

[119] Stone GW, Maehara A, Muller JE, Rizik DG, Shunk KA, BenYehuda $\mathrm{O}$, et al. Plaque Characterization to Inform the Pre- diction and Prevention of Periprocedural Myocardial Infarction during Percutaneous Coronary Intervention: the CANARY Trial (Coronary Assessment by near-infrared of Atherosclerotic Rupture-prone Yellow). JACC: Cardiovascular Interventions. 2016; 8: 927-936.

[120] Heusch G, Kleinbongard P, Böse D, Levkau B, Haude M, Schulz R, et al. Coronary microembolization: from bedside to bench and back to bedside. Circulation. 2009; 120: 1822-1836.

[121] Chowdhury MM, Singh K, Albaghdadi MS, Khraishah H Mauskapf A, Kessinger CW, et al. Paclitaxel Drug-Coated Balloon Angioplasty Suppresses Progression and Inflammation of Experimental Atherosclerosis in Rabbits. JACC: Basic to Translational Science. 2020; 5: 685-695.

[122] Her A, Shin E, Chung J, Kim YH, Garg S, Lee JM, et al. Plaque modification and stabilization after paclitaxel-coated balloon treatment for de novo coronary lesions. Heart and Vessels. 2019; 34: 1113-1121.

[123] Ann SH, Balbir Singh G, Lim KH, Koo B, Shin E. Anatomical and Physiological Changes after Paclitaxel-Coated Balloon for Atherosclerotic De Novo Coronary Lesions: Serial IVUS-VH and FFR Study. PLoS ONE. 2016; 11: e0147057.

[124] Liu L, Liu B, Ren J, Hui G, Qi C, Wang J. Comparison of drugeluting balloon versus drug-eluting stent for treatment of coronary artery disease: a meta-analysis of randomized controlled trials. BMC Cardiovascular Disorders. 2018; 18: 46.

[125] Serruys PW, García-García HM, Buszman P, Erne P, Verheye S, Aschermann $\mathrm{M}$, et al. Effects of the direct lipoproteinassociated phospholipase A(2) inhibitor darapladib on human coronary atherosclerotic plaque. Circulation 2008; 118: 1172 1182 .

[126] Baigent C, Blackwell L, Emberson J, Holland LE, Reith C, Bhala $\mathrm{N}$, et al. Efficacy and safety of more intensive lowering of LDL cholesterol: a meta-analysis of data from 170000 participants in 26 randomised trials. The Lancet. 2010; 376: 1670 1681 . 